\title{
Actor network analysis to leverage improvements in conservation and development outcomes in Cambodia
}

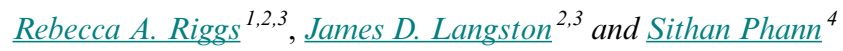

\begin{abstract}
Network analysis has emerged as a useful practice for characterizing governance relationships and providing insights to the power relations that affect landscapes. We applied actor network analysis in two rural Cambodian landscapes to examine decisionmaking structures that affect conservation and development systems. Using questionnaire data, we analyze structural features of networks of cooperation and exchange to identify patterns of action and processes of change. We supplement our analysis with qualitative information gathered on power and social-ecological components of landscapes to enrich our understanding of natural resource systems. We find that power in Cambodia is concentrated in a central hierarchy, and external actors aiming to influence decision making would benefit from operating at multiple scales; there is no single leverage point for interventions. Cooperation between conservation and development actors is lacking; we observe that actors tend to cluster within similar groups. Cross-sectoral collaboration may be enhanced by knowledge brokers, but current actors lack resources to fulfil this role and require external support. Our study highlights the importance of nongovernment actors as conveners and facilitators to shape natural resource governance in the context of weak institutions. We advocate more institutionalized use of diagnostics, such as actor network analysis, for enhanced natural resource governance.
\end{abstract}

Key Words: Actor network analysis; Cambodia; landscape transitions; natural resource governance; social-ecological systems

\section{INTRODUCTION}

Natural resource governance is composed of decisions that are made by numerous and diverse actors, all affecting policy and implementation outcomes. Understanding their influence, recognizing their agency, and achieving better coordination among these numerous and diverse actors is vital for achieving sustainable resource governance. Yet many conservation initiatives fail because organizations insufficiently grapple with the complexity of stakeholder characteristics and relationships. Network science, the science of analyzing networks, has emerged as a powerful contribution to natural resource governance by visualizing and analyzing these relationships. Applied to natural resource management (NRM), network science can help diagnose and analyze patterns and connectivity among actors involved in multiple elements of natural resource use and decision making (Bodin and Prell 2011). It can help identify influential actors and their mutual or conflicting interests and can provide insights to the power relations that determine development outcomes. Network science can enrich how decision makers understand the relationships between relevant actors so that they might more effectively channel resources to improve social, economic, and environmental outcomes.

Empirical evidence demonstrating the value of network science in natural resource governance continues to emerge (Downey 2010, Mills et al. 2014, Angst et al. 2018, Sari et al. 2019). Recent studies cite the utility of social network analysis (SNA) in understanding how local actors foster or hinder sustainable development (Ernstson et al. 2008, Bodin and Crona 2009, Hirschi 2010). Similarly, policy network analysis (PNA) has been used to study governance structures and how actors participate in and are recognized in decision-making processes (Brockhaus et al. 2014, Ndeinoma et al. 2018). In this paper, we combine and expand upon these two approaches and use the term actor network analysis (ANA) to describe the process of examining the relationships and structures of actors in a social-ecological system. We build from existing literature, recognizing the power of actors as decision makers or agents of change, as well as the importance of the structure of the network in influencing outcomes (Marsh and Smith 2000, Scott and Carrington 2011). An actor may represent an organization, individual, or group involved in decision-making processes. By using the concept ANA, we acknowledge that actors may exist at multiple scales, and network analysis should include both components of SNA, such as power and relationships, and PNA, such as governance structure and decision-making processes (Cash et al. 2006).

In natural resource systems, management and policy decisions often arise from complex arrangements of state and nonstate actors that engage with decision-making processes at multiple scales (Mwangi and Wardell 2012). In low- and middle-income countries, these natural resource systems are rapidly changing. The number of actors with different objectives is increasing across temporal and spatial scales (Nagendra and Ostrom 2012). In recent decades, there has been increased interest in understanding and influencing changes in "landscapes"- a desirable scale for understanding and influencing social-ecological systems (Arts et al. 2017). Landscape approach interventions aim to make longterm improvements to conservation, production, and livelihoods (Sayer et al. 2013, Reed et al. 2016). Efforts to transform these systems require understanding how decision-making processes take place and how to influence them (Sayer et al. 2016). Trajectories of change in landscapes are typically not the result of a single actor, but a constellation of actors working toward shared or conflicting objectives (Riggs et al. 2020a). Actors may represent diverse and dynamic values, beliefs, and preferences,

\footnotetext{
${ }^{1}$ Centre for Tropical Environmental and Sustainability Science, College of Science and Engineering, James Cook University, Cairns, Australia, ${ }^{2}$ Faculty of Forestry, University of British Columbia, Vancouver, Canada, ${ }^{3}$ Tanah Air Beta, Bali, Indonesia, ${ }^{4}$ Wildlife Conservation Society, Cambodia Program
} 
informed by knowledge generated at higher scales (global or national policy making) or local scales (household or village norms). These knowledge systems affect governance systems, from individual preferences to institutionalized processes, such as policy, legislation, and market systems (Rathwell et al. 2015, Langston et al. 2019). Landscapes are where knowledge and governance interactions result in lived and observable outcomes. Actor network analysis can provide insights into how and why decisions are made in landscapes and how decisions shape social and environmental outcomes.

In this paper, we use ANA and complementary qualitative information to examine two landscapes in Cambodia where conservation and development are in conflict, and actors are trying to improve natural resource governance. We ask the following questions: (1) which actors influence landscape development outcomes? (2) how do governance arrangements determine conservation and development outcomes? (3) how can institutional arrangements be leveraged to contribute to better management of landscapes? The results of our analysis have implications for the use of ANA in landscape-scale initiatives and the methodological application of network science in natural resource governance.

\section{Why Networks?}

Actor networks are comprised of individuals, groups, or organizations (government and nongovernment) connected with each other through decision-making relationships in domains such as policy, problem solving, management, and conflict resolution. Actor network analysis considers the substantive traits of decision-making networks, focusing on influence, patterns of information sharing, and how relationships enhance or inhibit functionality. Landscape-scale ANA attempts to achieve a compromise among network analyses approaches. By focusing at the landscape scale, we acknowledge that network analysis cannot capture the full extent of social relations that influence conservation and development outcomes. As identified by Emirbayer and Goodwin (1994), network analysis is constrained by the challenges of capturing the dynamic nature of societal change and the diversity of signals that inform behavior and decision making. Actor network analysis does not attempt to assign cultural meaning to networks; much more indepth ethnographic approaches are necessary to comprehend this kind of complexity (Marshall and Staeheli 2015). As a stand-alone process, ANA may overlook important power dynamics that exist within communities (Leach et al. 1999). Yet by focusing on decision-making networks, ANA can be one of the multiple diagnostic tools to examine how power is wielded within governance structures (Avelino and Wittmayer 2016, Morrison et al. 2017). Actor network analysis does not exclusively focus on formal agencies but examines the roles and perceptions of all types of actors involved in decision making. It embraces concepts of polycentricity and acknowledges the "uneven capacity" of different actors to influence the goals, processes, and outcomes of natural resource governance (Morrison 2017). Although ANA is limited by the production of a static network, the purpose of the exercise is not to cement the status quo, but to raise questions as to how to improve functionality of governance systems. The identification of network characteristics, such as leverage points, influential actors, knowledge brokers (Meyer 2010), patterns of interactions, power dynamics, and synergistic goals, is intended to help to guide this process.
The utility of network science to support NRM is well argued in the literature (Bodin et al. 2006, Prell et al. 2009, de Lange et al. 2019, Groce et al. 2019). However, if NRM challenges stem from broader issues within governance systems, there may be a need to dive deeper into actors, structures, and processes that are preventing social and environmental sustainability. Conservation and development initiatives frequently occur in the context of weak institutions (Barrett et al. 2006, Clements et al. 2010). Institutions, the mechanisms and formal and informal rules that shape behavior and decision making, are critical to ensuring functionality of governance within landscape transitions, including property rights, managing common-pool resources, creating sustainable livelihoods, and preventing degradation and depletion of resources (Cleaver 2017). Challenges in NRM arise when institutions are not capable of navigating complexities of these systems and responding to social-economic-ecological needs (Bull et al. 2014, Riggs et al. 2018a). Without imposing a normative framework for improving NRM, examining networks may help to identify institutional challenges perceived by landscape actors and how governance arrangements can facilitate or hinder desired outcomes (Crona and Hubacek 2010).

Andrews et al. (2017) argue that successful policy implementation (effective functioning) stems less from good institutions, but instead it is effective functioning that builds good institutions. They suggest three processes for effective implementation of initiatives: (1) leveraging - identifying charismatic and wellconnected actors to build internal and external support, (2) convening - creating interorganizational arrangements that bring together different people and resources, and (3) connectingcreating indirect ties between actors to facilitate broad interaction. The strengthening and use of networks may then encourage learning between actors as changes occur and new ideas emerge and actors make progress toward shared goals. Networks may become "communities of practice" (Wenger 1999), in which relationships of mutual engagement are bound together by shared concerns and actions. Communities of practice may cultivate expertise (Goldstein and Butler 2010) and drive incremental change toward functioning governance systems (Arts and de Koning 2017). As shown by Lubell (2003) in a study of estuary stakeholders in the USA, in a virtuous circle, interactions can lead to cooperation and consensus, and if actors perceive effectiveness, they may be reaffirmed in their decision to take collective action. We contend that understanding how this process may occur in different contexts requires indepth knowledge of power and influence, mechanisms for mobilization and information sharing, and network structures.

\section{RESEARCH METHODS}

\section{Research Setting}

We conducted ANA as part of broader research on the socialecological impacts of landscape transitions in Cambodia. As a country focused on peace building and economic growth, Cambodia exhibits both high rates of natural resource depletion and growth in prosperity. Cambodia's economy has sustained an average GDP growth rate of 8\% between 1998 and 2018 (World Bank 2019), and forest cover has declined from $72 \%$ in 1990 to 52\% in 2015 (Food and Agriculture Organization (FAO) 2015). In rural areas, large portions of intact forest are being designated for private enterprise in industrial agriculture or mining at the expense of tropical biodiversity (Davis et al. 2015). With improved 
capabilities and resources, smallholders are expanding agricultural land into natural forest (Travers et al. 2015). Although the agrarian transition has the potential to lead to permanent livelihood improvements, serious concerns are being raised over the degree to which globally significant biodiversity can continue to exist in transformed rural landscapes (Mahood et al. 2016, Nuttall et al. 2017, Riggs et al. 2018b). Scheidel (2016) and Neef et al. (2013) describe the expansion of agribusiness at the expense of local livelihoods. Actors engaged in conservation and development must make difficult management decisions: how to move through an agrarian transition while ensuring inclusive growth with minimal environmental harm.

\section{Study Sites}

We completed two ANAs, the first in Preah Vihear province in northern Cambodia and the second in Mondulkiri province on the eastern border of Cambodia and Vietnam. In each province, we delineated a landscape of interest (Fig. 1). Landscape delineation was determined by the emergent problems of each place. The delineations were a synthesis of diverse perspectives of problems, by local communities and regional and national natural resource-oriented organizations. The two landscapes, the Northern Plains and the Eastern Plains, show characteristics of many of the rural landscapes in Southeast Asia; rapid land-use change, high poverty, and global interests in protecting areas of high conservation value (Riggs et al. 2020a). Forests and agricultural areas are habitat for threatened flora and fauna. Both landscapes consist of protected area networks managed by the Ministry of Environment with support from nongovernmental organizations (NGOs). Until recently, forest conservation responsibilities in Cambodia were divided among the Forestry Administration under the Ministry of Agriculture, Fisheries, and Forestry (MAFF) and the Ministry of Environment (MoE). In April 2016, subdecree no. 69 transferred all protected areas to the MoE. The MAFF is responsible for economic land concessions and community forests outside of protected areas, as well as conservation areas and community fisheries managed by the Fisheries Administration within the MAFF (Souter et al. 2016). Control of protected areas has also recently shifted from the central government to the provincial government. Consequently, decisions regarding protected areas must be passed through the Provincial Department of Environment (PDoE) and the provincial administration.

A number of protected areas in Cambodia are supported by conservation NGOs, which provide additional resources and strengthen government capacity (Paley 2015). In the two study sites, the PDoE works closely with conservation NGOs and with government and nongovernment stakeholders for land-use planning and community development. With growing attention on development opportunities, protected area managers also engage with various private and government agencies representing agriculture, mining, indigenous land tenure, and construction. The proximity of the protected landscapes to Cambodia's neighbors necessitates engagement with the military, although this is more apparent in the Northern Plains. Detailed descriptions of the social and biophysical aspects of the two landscapes can be found in Clements (2012) and Travers et al. (2015). For the purpose of this study, the "landscape" concept is defined by the actor's perceptions of their social and environmental systems - the landscapes do not have fixed boundaries. The landscapes depicted in Fig. 1 are, therefore, reference points, but not exact representations of the areas studied.

Fig. 1. Northern Plains Landscape and Eastern Plains Landscape in Cambodia. The study focused on three villages within each landscape and actors present at the commune, district, and provincial levels. Spatial data obtained from Wildlife Conservation Society Cambodia Program. Complete data on ELCs and SLCs are unavailable.

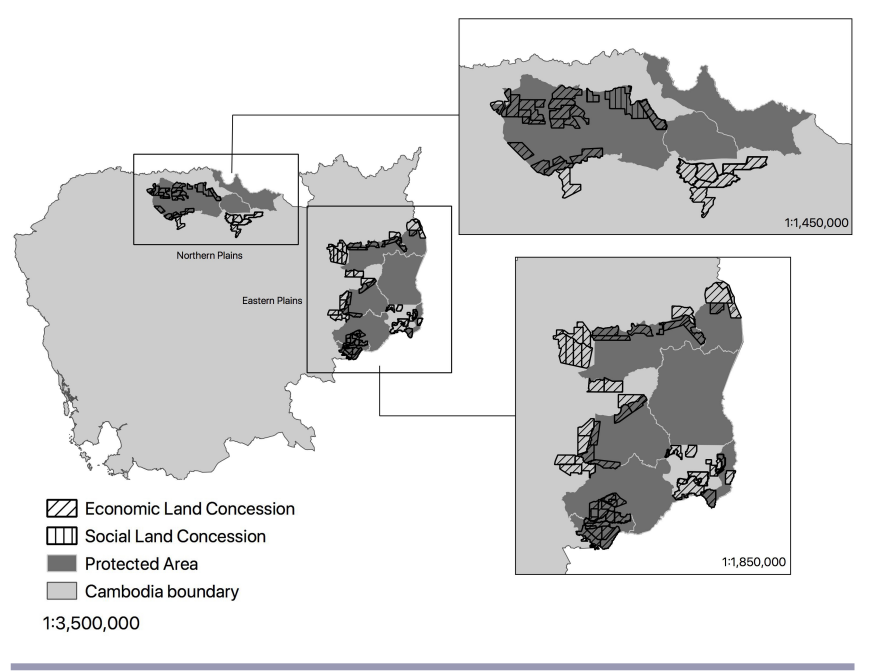

\section{Data Collection}

We interviewed 64 actors involved in conservation and development initiatives in two landscapes from November 2017 to February 2018. Our sampling approach was two-pronged. We purposively selected actors to capture the full range of diversity of actors related to the problems identified in each landscape. We also selected using a chain referral, or snowballing process (Newing 2010). First, we consulted managers of the protected areas and then sought-out the key actors mentioned during the interview process. The two-pronged approach, the purposive and chain-referred interviews, allowed for approximately equal representation of government and civil society (NGOs and representatives of local community groups) (Table 1). We selected provincial government departments involved in NRM and infrastructure development, as well as local authorities from the Ministry of Interior at the district, commune, and village level. Approximately half of the actors interviewed operated at the provincial scale or above (national or international), the second half operated at district level or below. We encountered challenges in connecting with companies and were unable to interview representatives from the private sector but allowed respondents to include private-sector actors in their response.

Interviews were arranged ahead of time by phone call or letter and were conducted in the respondent's place of work, by an experienced research assistant and the primary author. For interviewees who did not have a place of work (i.e., community organization representative), the interview was conducted at their home. Interviews were mostly conducted in the Khmer language. Conversations were translated as needed throughout the interview 
to allow for ease of discussion, and notes were recorded in English. Some respondents preferred to speak in English as Khmer was not their native language or they felt comfortable speaking in the author's native language. The majority of interviews were conducted with individuals. In some cases, small groups were present (two to three people), but one individual provided the responses. As the primary author and research assistant were not residents of the landscapes and had no prior connection to the interviewee, each meeting began with personal introductions and information about the research.

Table 1. Categories of actors interviewed; actors are categorized by type

\begin{tabular}{lcc}
\hline \hline Category of respondents & EP & NP \\
\hline Armed Forces (Police) & 2 & 1 \\
Civil Society Group $^{\dagger}(\mathrm{CPA}, \mathrm{ICT}$, Ecotourism) & 2 & 8 \\
Development NGO $^{\dagger}$ & 5 & 5 \\
Government (Provincial Departments, Village, Commune, & 17 & 16 \\
and District Authorities, PA Authorities) & 4 & 4 \\
Natural Resource Management NGO & \\
Total & 30 & 34 \\
\hline${ }^{\dagger}$ Community Protected Area Committee (CPA), Indigenous Communal \\
Titling Committee (ICT) \\
${ }^{\dagger}$ Most NGOs engaged in both conservation and development. They are \\
categorized here by main activities.
\end{tabular}

Each respondent answered eight questions, covering information sharing, influence, cooperation, evidence for decision making, principles, goals, and actors or conditions that prevent the landscape from functioning. Prior to interviewing, we ensured each respondent understood they could list an individual, organization (government or nongovernment), private company or civil society group in their response. We asked that respondents refer to the specific landscape studied when answering questions and explained that landscapes could geographically include areas containing vegetation, agriculture, and settlements. Questions were brief and interviews took approximately 45 minutes to complete. The openness of respondents varied, with some respondents voluntarily elaborating on answers and sharing concerns, and others responding to the questions without elaboration. To minimize potential issues of translation, the author and research assistant reviewed notes following each interview to achieve translation precision.

Additional information on the landscapes was collected through key informant interviews, observations, and informal discussions. Given the geographic size of the area, local authorities and groups were selected in three villages that were studied in depth in each landscape. Interactions at the village level ensured responses could be verified with observed conditions and additional data collected in each site. As both landscapes are subject to long-term conservation initiatives, available information included forest cover, biodiversity surveys, and socioeconomic household surveys (Rainey et al. 2010, Beauchamp et al. 2018, Griffin 2019, Riggs et al. 2020a). The authors personally conducted interviews with local communities, organizations, and authorities in each of the three villages to discuss landscape change, institutions, natural resources, and well-being. Details of these interviews and the resulting analysis and discussion can be found in Riggs et al. (2020a). Due to the sensitivity of the information, NGOs are not individually identified; instead, we refer broadly to types of organizations involved in conservation and development activities in Cambodia.

\section{Data Analysis}

We analyzed the network data collected using an open source social network analysis software called Gephi (Gephi Consortium 2014). Each actor is represented by a circular "node," and each relationship with another actor is linked with a line called an "edge." If one organization had multiple respondents, we grouped the respondents into a single actor (node) in the landscape (i.e., three village heads were grouped into a single village administration). We created three networks for each landscape providing graphical visual representations of (1) information sharing, (2) cooperation, and (3) evidence for decision making. We used weighted edges in the information sharing network based on frequency of communication. We assigned a weight of [5] if actors communicated more than monthly, [4] more than quarterly, [3] when necessary, [2] more than biannually, [1] more than annually. Edges were assigned directions according to one-way or two-way information sharing between actors as stated by the respondent. Weighted edges were given to the cooperation sharing network based on how well the respondent felt the two actors cooperated. This information was obtained during the interview, when respondents were asked to rank cooperation with other actors: [1] some, [2] moderate, [3] high.

We adjusted the visual representation of the graph using the display algorithms and ran a series of statistical metrics for deeper insight into the network structure and properties. We first obtained the modularity for each graph to determine how much the network clusters. We then calculated the betweenness, eigenvector, and closeness centrality, as well as the clustering coefficient and degree (described in Appendix 1). We then used UCINET (Borgatti et al. 2002) Key Player add-on to identify the set of key players in the cooperation networks and information networks in each landscape (Borgatti 2006). Key players can be identified through two types of problems: (1) Key Player Problem/ Negative (KPP-Neg), which identifies which actors (nodes), if removed, maximally fragment the network, and (2) Key Player Problem/Positive (KPP-Pos), which seeks to identify actors (nodes) that are maximally connected to other actors (Borgatti 2006). First, we identified the key player set in the cooperation networks to find the actors who are key for maintaining cooperation (such that their removal would result in maximum disruption to the network, KPP-Neg). Second, we identified the key player set in the information sharing network to find the set of key players for diffusing information or attitudes, problem type KPP-Pos. For each network, we selected a fixed set of three key players.

\section{RESULTS}

\section{Goals and Perceived Constraints}

Almost all actors identified multiple goals, demonstrating a holistic approach to reaching objectives and multidimensional understanding of the issues. Local authorities (village and commune) identified more goals than other actors, likely due to the wide of range of responsibilities of the position and their proximity to both people living in the landscapes and institutions. Actor goals included improved governance and law enforcement, conservation, sustainable resource use, and health. The most frequently identified goal was improved living standards, 
identified by $48 \%$ of actors. Provincial government departments and local authorities focused on strengthening current roles and activities of government bodies, including following national plans, issuing information, land-use planning, and law enforcement. Their goals tended to be predetermined, reflecting mission statements, rather than a responsive goal to a democratically identified set of needs in the particular landscape. In Mondulkiri, actors gave more attention to the needs of indigenous people and land-use planning, likely due to the competition for land and high number of self-identified indigenous communities living in the area in contrast to the Northern Plains.

In general, respondents were reluctant to discuss or name actors that prevented the landscape from functioning as well as it could. Nongovernmental organizations were more willing to make those "barrier actors" explicit. To enrich the question, we asked respondents what the key challenges were in the landscape and constraints to improving social and environmental outcomes (Table 2). Common challenges preventing landscape functionality identified by actors in both the Northern Plains and Eastern Plains included corruption, conflict, lack of cooperation, failure to uphold the law, and unclear boundaries. Lack of infrastructure such as roads and transmission lines add difficulty for actors when performing their tasks, but respondents also identified internal constraints, such as funding, the short-term nature of projects, and lack of capacity. During our time spent in villages, we were told poor health, low education, and a lack of willingness to engage also prevented actors from meeting their objectives. Government departments and law enforcement groups were identified as actors preventing landscapes from functioning, due to their perceived role in facilitating corruption and power imbalances. This was reported as an issue from government and nongovernment actors during the network interviews and in villages, indicating consensus that weak institutions are a major issue in both landscapes.

\section{Cooperation and Clusters}

During interviews, respondents were asked to list actors they cooperated with, assign a value to the level of cooperation ((1) some, (2) moderate, (3) high), and identify actors with whom they desire better cooperation. Cooperation networks for both landscapes are displayed in Fig. 2. Nodes represent actors, and edges are weighted by the level of cooperation. For each network, we calculated the clustering coefficient and divided the nodes by modularity to determine clusters: groups of strongly connected nodes (Khokhar 2015). In the Northern Plains cooperation network, five clusters were identified, representing (1) development (2) NRM (3) human rights (4) government, and (5) agriculture. Clusters did not represent distinct objectives. Clustering shows that development NGOs cooperated well with provincial departments engaged in development, but there was little cooperation with actors engaged in NRM. Similar patterns were seen in the information sharing and evidence for decisionmaking networks.

In Mondulkiri, network clustering was less likely (lower clustering coefficient), and it was more difficult to identify distinct clusters of actors. As seen in Fig. 2, similar groups are identified in the Eastern Plains and Northern Plains, but clusters overlap to a greater degree. In addition, a separate cluster emerged, agroforestry, consisting mostly of private-sector actors in agribusiness. Lower clustering in the Eastern Plains is likely due to the recent and fast-paced changes that we observed in the landscape, such as the entry of new private-sector actors and immigration. Disruption to the landscape inspired the need for greater integration between sectors, leading to a more tightly entwined network, such as NGOs engaged in multiple activities in conservation, tourism, health, and land-use planning. With fewer disruptions and fewer organizations over a large geographical area, Northern Plains actors appear likely to remain within their sectors.

Table 2. Constraints preventing landscape from functioning as well as it could according to respondents

\begin{tabular}{|c|c|c|}
\hline Type of Constraint & NPEP & Example \\
\hline Infrastructure & $\mathrm{X} \mathrm{X}$ & Difficult road, poor phone reception \\
\hline Environmental & $\mathrm{X} X$ & Natural hazards, remoteness \\
\hline $\begin{array}{l}\text { Knowledge, capacity } \\
\text { and engagement }\end{array}$ & & $\begin{array}{l}\text { Lack of legal knowledge among local } \\
\text { communities }\end{array}$ \\
\hline Spatial & $\mathrm{X}$ & $\begin{array}{l}\text { Communities restricted from expanding } \\
\text { agricultural land in protected areas }\end{array}$ \\
\hline Illegal activities & $\mathrm{X} \mathrm{X}$ & Illegal logging and hunting \\
\hline Market & & $\begin{array}{l}\text { Market fluctuation, limited market } \\
\text { opportunities }\end{array}$ \\
\hline Demographics & $\mathrm{X} X$ & Immigration to area \\
\hline Governance & $\mathrm{X} X$ & Land conflict, corruption, insecure tenure \\
\hline Financial & $\mathrm{X}$ & Lack of investment in development \\
\hline
\end{tabular}

Fig. 2. Cooperation Network for Northern Plains landscape (Left) and the Eastern Plains (Right). Nodes are colored by modularity class (cluster group). In EP, similar shades are used to distinguish nodes identified as seperate clusters but with similar characteristics. The graphs are displayed using Force Atlas layout algorithm. Nodes with high indegrees are located in the center of the graph.

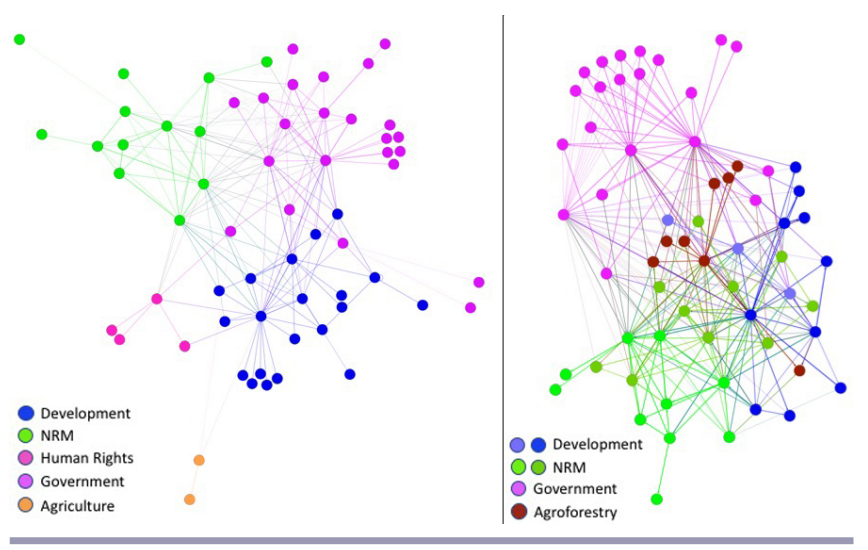

\section{Influence and Centrality}

In both the Northern Plains and Mondulkiri, respondents ranked the commune administration as the most influential actor in the landscape. Perceived influence was mainly due to the responsibilities of the commune administration; they are the primary institution responsible for the commune development plan and investment and must work with provincial departments 
Table 3. Key actors and centrality scores for the information sharing network in NP and EP. Degree and Influence are normalized values $(\mathrm{N})$. Actors are categorized by the highest level they operate $(\mathrm{C}=\mathrm{Commune}, \mathrm{P}=$ Province, $\mathrm{D}=\mathrm{District}, \mathrm{V}=\mathrm{Village})$ and by type ( $\mathrm{G}=$ Government, $\mathrm{N}=\mathrm{NGO}, \mathrm{AF}=$ Armed Forces $)$.

\begin{tabular}{|c|c|c|c|c|c|c|c|c|c|c|c|c|}
\hline \multirow[t]{2}{*}{ Actor } & \multirow[t]{2}{*}{ Level } & \multirow[t]{2}{*}{ Type } & \multicolumn{2}{|c|}{ Degree $(\mathrm{N})$} & \multicolumn{2}{|c|}{ Closeness } & \multicolumn{2}{|c|}{ Betweenness } & \multicolumn{2}{|c|}{ Eigenvector } & \multicolumn{2}{|c|}{ Influence $(\mathrm{N})$} \\
\hline & & & $\mathrm{NP}$ & EP & $\mathrm{NP}$ & EP & $\mathrm{NP}$ & EP & NP & $\mathrm{EP}$ & NP & EP \\
\hline Commune Administration & $\mathrm{C}$ & $\mathrm{G}$ & 0.44 & 0.52 & 0.59 & 0.32 & 0.05 & 0.05 & 0.74 & 1 & 0.43 & 0.48 \\
\hline Provincial Administration & $\mathrm{P}$ & G & 0.26 & 0.26 & 0.53 & 0 & 0 & 0 & 0.56 & 0.87 & 0.29 & 0.38 \\
\hline NRM NGO & $\mathrm{P}$ & $\mathrm{N}$ & 0.36 & 0.45 & 0.56 & 0.41 & 0.03 & 0.02 & 0.6 & 0.5 & 0.28 & 0.4 \\
\hline Dept. Environment & $\mathrm{P}$ & G & 0.4 & 0.55 & 0.57 & 0.4 & 0.05 & 0.04 & 0.63 & 0.89 & 0.28 & 0.27 \\
\hline Dept. Agriculture, Forests \& Fisheries & $\mathrm{P}$ & G & 0.18 & 0.62 & 0.51 & 0.53 & 0.01 & 0.07 & 0.38 & 0.57 & 0.25 & 0.14 \\
\hline Dept. Rural Development & $\mathrm{P}$ & G & 0.28 & 0.95 & 0.53 & 0.64 & 0.06 & 0.12 & 0.5 & 0.3 & 0.24 & 0.32 \\
\hline District Administration & $\mathrm{D}$ & G & 0.44 & 0.62 & 0.59 & 0.44 & 0.08 & 0.1 & 0.72 & 0.69 & 0.24 & 0.24 \\
\hline Military & $\mathrm{P}$ & $\mathrm{AF}$ & 0.08 & 0.1 & 0.4 & 0 & 0 & 0 & 0.14 & 0.43 & 0.2 & 0.09 \\
\hline Dept. Public Works and Transport & $\mathrm{P}$ & $\mathrm{G}$ & 0.04 & 0.17 & 0.45 & 0.33 & 0 & 0 & 0.12 & 0.19 & 0.19 & 0.19 \\
\hline Village Authority & $\mathrm{V}$ & G & 0.34 & 0.43 & 0.55 & 0.36 & 0.03 & 0.05 & 0.61 & 0.94 & 0.16 & 0.18 \\
\hline $\begin{array}{l}\text { Dept. Land Management, Urban Planning \& } \\
\text { Construction }\end{array}$ & $\mathrm{P}$ & G & 0.58 & 0.64 & 0.6 & 0.59 & 0.13 & 0.03 & 0.7 & 0.13 & 0.13 & 0.13 \\
\hline Office Chief (PA management) & $\mathrm{P}$ & G & 0.04 & 0.14 & 0.38 & 0.33 & 0 & 0.01 & 0.07 & 0.3 & 0 & 0.02 \\
\hline Dept. Planning & $\mathrm{P}$ & G & 1 & 1 & 0.78 & 0.71 & 0.48 & 0.02 & 1 & 0.09 & 0.02 & 0.08 \\
\hline
\end{tabular}

and NGOs to fund and implement a wide range of activities. They are, therefore, responsible for identifying and prioritizing needs within the landscape and cooperating with appropriate actors to address those needs. As all interviewees operated at the landscape scale (including half at the district level or below), the prominence of the commune administration reflects the hierarchical power structure of the Cambodian Government. Responsibilities are devolved to the commune, but the commune administration defers to higher administrations for direction. The commune administration also has a high eigenvector centrality value, indicating proximity to influential actors. The NRM organization comanaging the protected areas ranked high in perceived influence in both landscapes, likely due to their high visibility as a natural resource manager in the two focus areas.

Centrality measures for information-sharing networks show specific actors in each network with high connectivity to other actors. Actors with high degree values, such as the Department of Rural Development and Department of Planning, reach a broader network of actors (Table 3). Both Departments have roles in diffusing information to a larger set of actors In both landscapes, the Department of Planning scored high values for degree and closeness centrality, demonstrating the Department's ease of accessibility to other actors in the network. In the Eastern Plains, actors with high perceived influence also exhibited high values for eigenvector centrality and medium values for betweenness centrality (Fig. 3). In contrast, actors in the Northern Plains with high eigenvector values are dispersed throughout the network. Actors representing the Armed Forces exhibited smaller degree values and were more likely to cooperate with actors in the same category. A comparison of centrality values is shown in Table 3 for the information network; however, our analysis is drawn from calculations completed on all three networks in each landscape.

\section{Key Players}

For the cooperation networks in each landscape, we identified the KPP-Neg set to determine three actors that are central for cooperation and network cohesion (Borgatti 2006). In the Northern Plains, solving KPP-Neg identified the key player set
Fig. 3. Information networks for the Northern Plains and Eastern Plains. Nodes are sized by (1) perceived influence (2) betweenness centrality and (3) eigenvector centrality. In the Northern Plains, actors perceived to have high influence do not align with actors with high betweenness centrality. Influential actors are spread throughout the network. In the Eastern Plains, actors with high perceived influence align with actors with high eigenvector centrality, indicating an integrated and influential cluster of actors in the network.

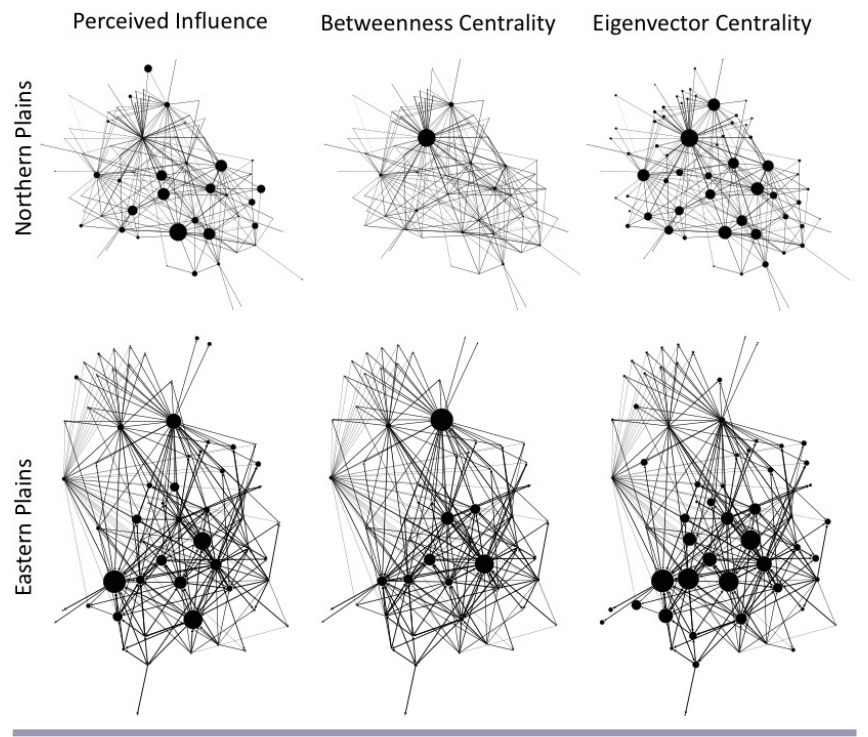

of the commune administration, a nongovernmental NRM organization, and a nongovernmental development organization, with fragmentation delta $12.8 \%$. In the Eastern Plains, solving KPP-Neg identified the key player set of the Department of Agriculture, Forests, and Fisheries, Department of Rural Development, and a nongovernmental NRM organization, with fragmentation delta $19 \%$. For the information networks, solving KPP-Pos identified three actors in each landscape to maximize 
the diffusion of information or behaviors. In the Northern Plains, the key player set identified the Department of Planning, the Economic Police, and a rights-based NGO that reaches $100 \%$ of the network. In the Eastern Plains, the KPP-Pos set identified three government bodies reaching $100 \%$ of the network: the Department of Rural Development, the Department of Planning, and the Department of Land Management, Urban Planning, and Construction. Figure 4 shows the location of the set of key players in each cooperation network.

Fig. 4. Cooperation network for the Northern Plains (top) and Eastern Plains (bottom) displayed in Netdraw (Borgatti et al. 2002). Key players in each network identified in red.
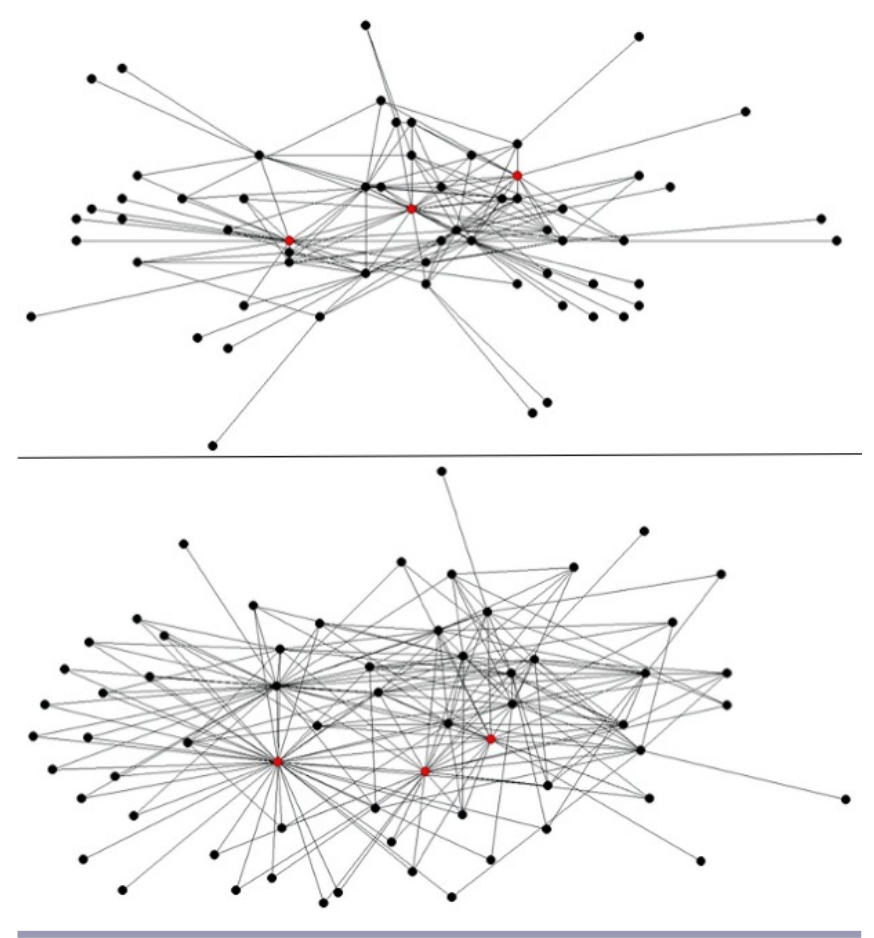

Evidence for Decision Making and Information Sharing

Most actors identified internal mechanisms for gathering evidence for decision making. For example, NGOs often collected data directly from the target area to develop a project focus. Actors at all levels stated they made decisions based on information gathered from local leaders and communities, which we directly observed in villages. We did not include a node representing local communities in the evidence network, and instead focus on evidence sharing between actors. In both landscapes, the local authorities, including village, commune, district, and provincial administrations, exhibit a high level of degree, indicating centrality in the network. High centrality and connectivity are likely due to institutional affiliation with the Ministry of Interior; they are responsible for passing information and up and down the government hierarchy. Among the local authorities, the district administration exhibits a higher level of degree, as it both gives and obtains information from a large number of actors, sitting at the center of the hierarchy. Although in all the networks we analyzed, government actors appear to have higher values of centrality, large NGOs follow closely behind in both landscapes in degree and eigenvector centrality. Their strong position in the network is representative of their close involvement with government actors in planning and strategizing within their sectors.

\section{DISCUSSION}

\section{Governance Arrangements for Conservation and Development Outcomes}

Our results show there is strong potential for conservation and development actors in rural landscapes in Cambodia to work collaboratively toward shared goals for sustainable development. In both the Northern Plains and Eastern Plains landscapes, actors identify a wide variety of social and environmental needs and holistic measures to achieve landscape goals. Collaborative working groups are in place in both landscapes, supporting cooperation and coordination between government and NGOs. Working groups convened quarterly meetings and provided opportunities for actors to communicate frequently and coordinate their actions. Our interviews with actors indicate the functionality of these networks had a visible impact on conservation and development outcomes in the landscape. For example, in both landscapes, NGOs and government actors involved in the health sector meet quarterly for strategic planning. Actors active in the health sector reported these activities were functioning well. When we asked people in villages to share their views on NGO activities, they frequently identified prominent health NGOs and the benefits of their programs.

Other sectors, such as NRM, demonstrated similar attributes of strong cooperation networks in small groups. Intersectoral collaboration is less frequent, despite shared landscape goals. In our interviews with government actors and in villages, conservation was rarely viewed as synergistic with development and, in some cases, identified as a major constraint to meeting development goals. However, the key player analysis shows that actors central to cooperation are spread across clusters, especially in the Northern Plains. Efforts to strengthen coordination and collaboration within the network may need to take into account the role of these actors in maintaining a cohesive network for landscape governance (Bodin and Crona 2009). For example, actors connecting clusters may be crucial for motivating progress toward shared goals, facilitating negotiations, and resolving conflict (Long et al. 2013).

In both landscapes, actors that successfully created interorganizational arrangements felt they were unable to effectively leverage these arrangements to make progress toward goals. The majority of respondents reported challenges in implementing activities, converging on two major limitations: (1) lack of support from stakeholders and (2) individuals abusing their position of power to serve patron-client relationships. The limitations are reflective of broader challenges in rural Cambodia, particularly in frontier areas such as the Eastern Plains (Mahanty and Milne 2015). Communities are resistant to conservation activities inhibiting their development, and authorities struggle to balance local needs with top-down directives (Riggs et al. 2020a). Conservation and development organizations find it difficult to gain wider support from other government bodies. Political willingness to fight corruption and engage with multiple stakeholders to solve complex social and environmental 
challenges is rare. The provincial and commune administrations have power to influence decisions made at the landscape scale, including the dispersion of commune budgets and allocation of resources. Yet the provincial administration has limited human capacity and financial resources to effectively carry out the designated responsibilities. The recent decentralization of power to the provincial scale has not been accompanied by adequate capacity building and resources. With greater responsibility and rising competing pressures for natural resources, actors at the landscape level need sufficient skills, knowledge, and resources to respond to local and global demands. In rural Cambodia, largescale changes to the landscape appear to be exogenous, either through large-scale investments or top-down directives, such as the designation of previously protected land as concession or private land. These externally made decisions do not involve provincial actors, offering little opportunity for actors to navigate potential impacts and repercussions at outcomes at the landscape scale.

\section{Leveraging Change through Networks}

Shared goals, interorganizational connectivity, yet perceived lack of effectiveness in the two landscapes raise questions of how governance functionality might be improved. Networks for natural resource governance may be enhanced by strong ties within clusters, knowledge brokers, constituencies at multiple levels of governance, support from diverse political bodies and sectors of society (Krackhardt et al. 2003, Newig et al. 2010, Bodin and Prell 2011, Alexander et al. 2016, Mbaru and Barnes 2017, McGonigle et al. 2020). The networks produced for the Northern Plains and Eastern Plains contain some of the characteristics described but are not functioning as well as they could.

Cross-sectoral agencies may be appropriate connectors to facilitate weak ties at the provincial level. Strengthening weak ties involves fostering relationships between groups, creating new channels for exchanging knowledge, ideas, and influence (Granovetter 1977). Identified as key players in information networks, the Departments of Planning and Rural Development are in an ideal position to connect ties between government and nongovernment actors, both within and across sectors, not necessarily to build collaboration, but to extend the reach of organizations interested in leveraging change. They may also be appropriate targets for diffusing knowledge for conservation or development initiatives (Mbaru and Barnes 2017). Similarly, as the actor with highest perceived influence over landscape-scale conservation and development outcomes, the commune administration may be important for leveraging political support for NRM. High eigenvector centrality and identification as a key player in the Northern Plains cooperation network support the commune administration's influence in decision-making networks. Each of these actors, the Departments of Planning and Rural Development, and the commune administration, have the potential to act as knowledge brokers but lack sufficient expertise and political independence. Their mandate is restricted to government plans, including the integration of commune and district development plans and the alignment of provincial development plans with national strategic plans.

The key player analysis also shows the importance of NGOs in maintaining cooperation and cohesion in both landscapes.
Nongovernmental organizations are invited to participate in government decision-making processes, integrating their activities and financial resources with proposed management plans at the commune, district, and provincial levels. Targeting and using these processes to support government actors to develop broad vision and comprehensive understanding of social and ecological context may help organizations and civil society gain consensus on priorities and mobilize resources (Riggs et al. $2020 b$ ). With interorganizational support, actors may be more willing to confront landscape challenges and inspire a process of change throughout the network. Organizations can nurture this process by convening actors to cogenerate knowledge, such that government and civil society share the same understanding of issues and evidence for decision making. In this role, external actors must be cognizant of local needs and power relations, particular in the framing of initiatives involving diverse actors (Lebel et al. 2018). Our interviews with local villagers suggested that the commune administration played a significant role in infrastructure and land-use decisions, but local leaders, either formally or informally elected, mobilize or demobilize action within the community. These insights reinforce the need to consider multiple levels of decision making in polycentric governance systems and the different ways in which influence is perceived and used.

\section{Limitations}

In our study, we selected organizations involved in conservation and development decisions at the landscape scale. However, decisions regarding large-scale development initiatives, with high impact in a landscape, are often made at a higher level of governance. For example, NGOs conducting participatory landuse planning with rural communities have been forced to adjust their planning to spatial plans outside of their control, hindering trust and progress made with communities. Understanding these patterns of change requires complementing ANA with qualitative information, ensuring the scope of analysis is not restricted by location or respondents. Networks are simplistic representations of reality, they do not comprehensively map all communication and coordination. Sampling in this study was strategically designed to capture a wide range of actors in natural resource governance and allow for interviews with prominent actors as they emerged. The multilevel, polycentric nature of governance in a "telecoupled" and globalized world raises fundamental challenges for network analysis. Our networks were limited by our interview data-a trade-off we were willing to accept in return for the richness gained through personal perspectives and inperson discussion. Saturation points used in qualitative research offer guidelines for data collection, but these must be adopted in conjunction with locally specific information on governance structures.

By focusing on decision-making networks at the landscape scale, we inevitably excluded important decision-making structures within villages and communities. Acknowledging issues of exclusion and equity in natural resource decisions (West et al. 2006, Shackleton et al. 2011), our limited focus on landscape-scale interactions is not intended to downplay these concerns. This study was embedded in transdisciplinary research that covers social-economic-ecological processes across scales. Actors that draw from this study to inform decisions will also draw from knowledge generated within communities and at higher scales. 
Similarly, individual and institutional characteristics are not captured in the networks displayed above, yet we learned from our interviews that individuals are integral to leveraging change. Studies that focus on the role of individuals as change agents could further enhance implementation and adoption of policies and initiatives (Mbaru and Barnes 2017).

The networks described above are static representations of a dynamic social landscape. In conservation and development, actors enter and leave systems continuously, especially NGOs relying on short-term funding for projects. By nature, actor networks are unstable and unreliable. Dynamic network analysis allows the examination of network structure and properties over time as features of institutions change, relationships develop, and actors move in and out of the landscape. Given the pace of change in governance structures in Cambodia, dynamic network analysis may help capture influential actors driving change. For example, the conflict along the border of Cambodia and Thailand in 2008 and recent establishment of social land concessions in the Northern Plains introduced a large quantity of military actors into the landscape, shifting power structures. Similarly, industrial concessions have transformed rural landscapes, significantly affecting rural communities and conservation initiatives (Neef et al. 2013). The extent to which these concessions have affected power relations within Cambodian landscapes is not sufficiently captured in the above analysis due to the separation of exogenous influences with localized decision-making processes by respondents. Further studies examining how commodity production affects institutional arrangements should help reconcile conflicts between private sector investments and landscape-scale conservation and development initiatives (RosTonen et al. 2018).

\section{CONCLUSION}

In conservation and development initiatives, diverse actors can and should influence decision making. Yet, understanding how actors influence change and using this knowledge for better social and environmental outcomes locally and globally are challenging. In this paper, we present an actor network analysis of two landscapes in rural Cambodia where conservation and development are in competition. Recognizing that landscapes are heterogenous and drivers of change are often exogenous, the network analysis described above is enriched with qualitative information obtained through interviews and observations. Detailed information of institutional arrangements, challenges, and goals from a diverse range of actors ensured we captured complex local realities in our analysis and avoided simplistic assertions (Prell et al. 2009). The results of our study contribute to insights expanding the use of network science in natural resource governance. Rather than focusing on a specific question - such as the diffusion of information or attitudes - we were able to generate understanding of how different actors may hold complementary roles in decision-making networks. Our results do not offer a normative solution, but an exploration of ways in which local actors may nurture change toward improved governance. Further studies that promote the cogeneration of network analysis with actors in situ will continue to enhance methodological techniques for the application and utility of network analysis in strengthening natural resource governance.
Responses to this article can be read online at: http://www.ecologyandsociety.org/issues/responses. $\mathrm{php} / 11854$

\section{Acknowledgments:}

We acknowledge and thank the organizations and individuals that participated in this research and shared their valuable knowledge and time. We are grateful to the families and communities that hosted us in Cambodia. This study is part of PhD research on socialecological impacts of landscape transitions in southeast Asia. Funding for this paper was partially provided by the Skyrail Rainforest Foundation, QLD, Australia [23506, 2018].

\section{Data Availability:}

The data that support the findings of this study will be openly available in RAR (2020), "Governing Landscape Transitions in Cambodia", Mendeley Data, v1http://dx.doi.org/10.17632/4rhmjvbsvr.1 (DOI is reserved but not active). Ethical approval for this research study was granted by James Cook University, H6914.

\section{LITERATURE CITED}

Alexander, S. M., M. Andrachuk, and D. Armitage. 2016. Navigating governance networks for community-based conservation. Frontiers in Ecology and the Environment 14:155164. https://doi.org/10.1002/fee.1251

Andrews, M., L. Pritchett, and M. Woolcock. 2017. Building state capability: evidence, analysis, action. Oxford University Press, Oxford, UK. https://doi.org/10.1093/acprof:oso/9780198747482.001.0001

Angst, M., A. Widmer, M. Fischer, and K. Ingold. 2018. Connectors and coordinators in natural resource governance: insights from Swiss water supply. Ecology and Society 23(2): 1. https://doi.org/10.5751/ES-10030-230201

Arts, B., M. Buizer, L. Horlings, V. Ingram, C. van Oosten, and P. Opdam. 2017. Landscape approaches: a state-of-the-art review. Annual Review of Environment and Resources 42:439-463. https:// doi.org/10.1146/annurev-environ-102016-060932

Arts, B., and J. de Koning. 2017. Community forest management: an assessment and explanation of its performance through QCA. World Development 96:315-325. https://doi.org/10.1016/j. worlddev.2017.03.014

Avelino, F., and J. M. Wittmayer. 2016. Shifting power relations in sustainability transitions: a multi-actor perspective. Journal of Environmental Policy and Planning 18:628-649. https://doi. org/10.1080/1523908X.2015.1112259

Barrett, C. B., C. C. Gibson, B. Hoffman, and M. D. McCubbins. 2006. The complex links between governance and biodiversity. Conservation Biology 20:1358-1366. https://doi.org/10.1111/ j.1523-1739.2006.00521.X

Beauchamp, E., T. Clements, and E. Milner-Gulland. 2018. Assessing medium-term impacts of conservation interventions on local livelihoods in northern Cambodia. World Development 101:202-218. https://doi.org/10.1016/j.worlddev.2017.08.008 
Bodin, Ö., and B. I. Crona. 2009. The role of social networks in natural resource governance: what relational patterns make a difference? Global Environmental Change 19:366-374. https://doi. org/https://doi.org/10.1016/j.gloenvcha.2009.05.002

Bodin, Ö., B. Crona, and H. Ernstson. 2006. Social networks in natural resource management: what is there to learn from a structural perspective? Ecology and Society 11(2): R2. https://doi. org/https://doi.org/10.5751/es-01808-1102r02

Bodin, Ö., and C. Prell. 2011. Social networks and natural resource management: uncovering the social fabric of environmental governance. Cambridge University Press,Cambridge, UK. https:// doi.org/10.1017/CBO9780511894985

Borgatti, S. P. 2006. Identifying sets of key players in a social network. Computational and Mathematical Organization Theory 12:21-34. https://doi.org/10.1007/s10588-006-7084-X

Borgatti, S. P., M. G. Everett, and L. C. Freeman. 2002. Ucinet for Windows: software for social network analysis. Analytic Technologies, Harvard, Massachusetts, USA.

Brockhaus, M., M. Di Gregorio, and R. Carmenta. 2014. REDD+ policy networks: exploring actors and power structures in an emerging policy domain. Ecology and Society 19(4): 29. https://doi.org/10.5751/ES-07098-190429

Bull, G., C. Elliott, A. Boedhihartono, and J. Sayer. 2014. Failures in tropical forest and conservation policy: what is the solution? Journal of Tropical Forest Science 26:1-4.

Cash, D., W. N. Adger, F. Berkes, P. Garden, L. Lebel, P. Olsson, L. Pritchard, and O. Young. 2006. Scale and cross-scale dynamics: governance and information in a multilevel world. Ecology and Society 11(2): 8. https://doi.org/10.5751/ES-01759-110208

Cleaver, F. 2017. Development through bricolage: rethinking institutions for natural resource management. Routledge, London, UK. https://doi.org/10.4324/9781315094915

Clements, T. 2012. Money for something? Investigating the effectiveness of biodiversity conservation interventions in the northern plains of Cambodia. Dissertation, University of Cambridge, Cambridge, UK.

Clements, T., A. John, K. Nielsen, D. An, S. Tan, and E. MilnerGulland. 2010. Payments for biodiversity conservation in the context of weak institutions: comparison of three programs from Cambodia. Ecological Economics 69:1283-1291. https://doi. org/10.1016/j.ecolecon.2009.11.010

Crona, B., and K. Hubacek. 2010. The right connections: how do social networks lubricate the machinery of natural resource governance? Ecology and Society 15(4): 18. https://doi. org/10.5751/ES-03731-150418

Davis, K. F., K. Yu, M. C. Rulli, L. Pichdara, and P. D'Odorico. 2015. Accelerated deforestation driven by large-scale land acquisitions in Cambodia. Nature Geoscience 8:772-775. https:// doi.org/10.1038/ngeo2540

de Lange, E., E. Milner-Gulland, and A. Keane. 2019. Improving environmental interventions by understanding information flows. Trends in Ecology and Evolution 34:1034-1047. https://doi. org/10.1016/j.tree.2019.06.007
Downey, S. 2010. Can properties of labor-exchange networks explain the resilience of swidden agriculture? Ecology and Society 15(4): 15. https://doi.org/https://doi.org/10.5751/es-03686-150415

Emirbayer, M., and J. Goodwin. 1994. Network analysis, culture, and the problem of agency. American Journal of Sociology 99:1411-1454. https://doi.org/10.1086/230450

Ernstson, H., S. Sörlin, and T. Elmqvist. 2008. Social movements and ecosystem services-the role of social network structure in protecting and managing urban green areas in Stockholm. Ecology and Society 13(2): 39. https://doi.org/https://doi. org/10.5751/es-02589-130239

Food and Agriculture Organization (FAO). 2015. Global forest resources assessment 2015: desk reference. United Nations FAO, Rome Italy.

Gephi Consortium. 2014. Gephi. Computer program] (version 0.9.2) [online] URL: https://gephi.org/

Goldstein, B. E., and W. H. Butler. 2010. Expanding the scope and impact of collaborative planning: combining multistakeholder collaboration and communities of practice in a learning network. Journal of the American Planning Association 76:238-249. https://doi.org/10.1080/01944361003646463

Granovetter, M. S. 1977. The strength of weak ties. Pages $347-$ 367 inS. Leinhardt, editor. Socialnetworks: a developing paradigm. Academic Press, New York, New York, USA. https://doi.org/ https://doi.org/10.1016/b978-0-12-442450-0.50025-0

Griffin, O. 2019. Checklist of extant species recorded in Keo Seima Wildlife Sanctuary, Cambodia. Version 1.3. WCS Cambodia. Checklist dataset. [online] URL: https://doi.org/10.15468/ rxba 17

Groce, J. E., M. A. Farrelly, B. S. Jorgensen, and C. N. Cook. 2019. Using social-network research to improve outcomes in natural resource management. Conservation Biology 33:53--65. https://doi.org/10.1111/cobi.13127

Hirschi, C. 2010. Strengthening regional cohesion: collaborative networks and sustainable development in Swiss rural areas. Ecology and Society 15(4): 16. https://doi.org/10.5751/ ES-03714-150416

Khokhar, D. 2015. Gephi Cookbook. Packt Publishing Ltd., Birmingham, UK

Krackhardt, D., N. Nohria, and B. Eccles. 2003. The strength of strong ties. Pages 109-129 in R. Cross, A. Parker, and L. Sasson, editors. Networks in the knowledge economy. Oxford University Press, Oxford, UK.

Langston, J. D., R. A. Riggs, J. A. Sayer, C. Margules, and A. K. Boedhihartono. 2019. Science embedded in local forest landscape management improves benefit flows to society. Frontiers in Forests and Global Change 2: 3. https://doi.org/10.3389/ffgc.2019.00003

Leach, M., R. Mearns, and I. Scoones. 1999. Environmental entitlements: dynamics and institutions in community-based natural resource management. World Development 27:225-247. https://doi.org/10.1016/S0305-750X(98)00141-7

Lebel, L., M. Käkönen, V. Dany, P. Lebel, T. Thuon, and S. Voladet. 2018. The framing and governance of climate change 
adaptation projects in Lao PDR and Cambodia. International Environmental Agreements: Politics, Law and Economics 18:429446. https://doi.org/10.1007/s10784-018-9397-x

Long, J. C., F. C. Cunningham, and J. Braithwaite. 2013. Bridges, brokers and boundary spanners in collaborative networks: a systematic review. BMC Health Services Research 13: 158. https:// doi.org/10.1186/1472-6963-13-158

Lubell, M. 2003. Collaborative institutions, belief-systems, and perceived policy effectiveness. Political Research Quarterly 56:309-323. https://doi.org/10.1177/106591290305600306

Mahanty, S., and S. Milne. 2015. Conservation and development in Cambodia : exploring frontiers of change in nature, state and society. Routledge, Abingdon, UK.

Mahood, S. P., J. P. Silva, P. M. Dolman, and R. J. Burnside. 2016. Proposed power transmission lines in Cambodia constitute a significant new threat to the largest population of the critically endangered Bengal florican, Houbaropsis bengalensis. Oryx 52:147-155. https://doi.org/10.1017/S0030605316000739

Marsh, D., and M. Smith. 2000. Understanding policy networks: towards a dialectical approach. Political Studies 48:4-21. https:// doi.org/10.1111/1467-9248.00247

Marshall, D. J., and L. Staeheli. 2015. Mapping civil society with social network analysis: methodological possibilities and limitations. Geoforum 61:56-66. https://doi.org/10.1016/j. geoforum.2015.02.015

Mbaru, E. K., and M. L. Barnes. 2017. Key players in conservation diffusion: using social network analysis to identify critical injection points. Biological Conservation 210:222-232. https://doi.org/10.1016/j.biocon.2017.03.031

McGonigle, D. F., G. Rota Nodari, R. L. Phillips, E. Aynekulu, N. Estrada-Carmona, S. K. Jones, I. Koziell, E. Luedeling, R. Remans, K. Shepherd, D. Wiberg, C. Whitney, and W. Zhang. 2020. A knowledge brokering framework for integrated landscape management. Frontiers in Sustainable Food Systems 4: 13. https:// doi.org/10.3389/fsufs. 2020.00013

Meyer, M. 2010. The rise of the knowledge broker. Science communication 32:118-127. https://doi.org/10.1177/1075547009359797

Mills, M., J. G. Álvarez-Romero, K. Vance-Borland, P. Cohen, R. L. Pressey, A. M. Guerrero, and H. Ernstson. 2014. Linking regional planning and local action: towards using social network analysis in systematic conservation planning. Biological Conservation 169:6-13. https://doi.org/10.1016/j.biocon.2013.10.015

Morrison, T. H. 2017. Evolving polycentric governance of the Great Barrier Reef. Proceedings of the National Academy of Sciences114 (15): E3013-E3021. https://doi.org/10.1073/pnas.1620830114

Morrison, T. H., W. N. Adger, K. Brown, M. C. Lemos, D. Huitema, and T. P. Hughes. 2017. Mitigation and adaptation in polycentric systems: sources of power in the pursuit of collective goals. Wiley Interdisciplinary Reviews: Climate Change 8: e479. https://doi.org/10.1002/wcc.479

Mwangi, E., and A. Wardell. 2012. Multi-level governance of forest resources. (Editorial to the special feature.) International Journal of the Commons 6(2):79-103. https://doi.org/https://doi. org/10.18352/ijc. 374
Nagendra, H., and E. Ostrom. 2012. Polycentric governance of multifunctional forested landscapes. International Journal of the Commons 6(2):104-133. https://doi.org/10.18352/ijc.321

Ndeinoma, A., K. F. Wiersum, and B. Arts. 2018. The governance of indigenous natural products in Namibia: a policy network analysis. Environmental Management 62:29-44. https://doi. org/10.1007/s00267-017-0968-3

Neef, A., S. Touch, and J. Chiengthong. 2013. The politics and ethics of land concessions in rural Cambodia. Journal of Agricultural and Environmental Ethics 26:1085-1103. https://doi. org/10.1007/s10806-013-9446-y

Newig, J., D. Günther, and C. Pahl-Wostl. 2010. Synapses in the network: learning in governance networks in the context of environmental management. Ecology and Society 15(4): 24. https://doi.org/10.5751/ES-03713-150424

Newing, H. 2010. Conducting research in conservation: social science methods and practice. Routledge, London, UK. https:// doi.org/10.4324/9780203846452

Nuttall, M., M. Nut, V. Ung, and H. O'Kelly. 2017. Abundance estimates for the endangered Green Peafowl Pavo muticus in Cambodia: identification of a globally important site for conservation. Bird Conservation International 27:127-139. https:// doi.org/10.1017/S0959270916000083

Paley, R. 2015. Managing protected areas in Cambodia: the challenge for conservation bureacracies in a hostile governance environment. Pages 141-159 in S. Mahanty and S. Milne, editors. Conservation and development in Cambodia: exploring frontiers of change in nature, state and society. Routledge, Abingdon, UK. https://doi.org/https://doi.org/10.4324/9781315887302

Prell, C., K. Hubacek, and M. Reed. 2009. Stakeholder analysis and social network analysis in natural resource management. Society and Natural Resources 22:501-518. https://doi. org/10.1080/08941920802199202

Rainey, H., H. Bauran, and T. Evans. 2010. Forest cover trends in the northern plains of Cambodia 2002-2010. Wildlife Conservation Society, Phnom Penh, Cambodia.

Rathwell, K., D. Armitage, and F. Berkes. 2015. Bridging knowledge systems to enhance governance of environmental commons: a typology of settings. International Journal of the Commons 9(2):851-880. https://doi.org/10.18352/ijc.584

Reed, J., J. van Vianen, E. L. Deakin, J. Barlow, and T. Sunderland. 2016. Integrated landscape approaches to managing social and environmental issues in the tropics: learning from the past to guide the future. Global Change Biology 22:2540-2554. https://doi. org/10.1111/gcb.13284

Riggs, R. A., J. D. Langston, E. Beauchamp, H. Travers, S. Ken, and C. Margules. 2020a. Examining trajectories of change for prosperous forest landscapes in Cambodia. Environmental Management 66:72-90. https://doi.org/https://doi.org/10.1007/ s00267-020-01290-9

Riggs, R. A., J. D. Langston, C. Margules, A. K. Boedhihartono, H. S. Lim, D. A. Sari, Y. Sururi, and J. Sayer. 2018a. Governance Challenges in an Eastern Indonesian Forest Landscape. Sustainability 10:169. https://doi.org/https://doi.org/10.3390/ su10010169 
Riggs, R. A., J. D. Langston, and J. Sayer. 2018b. Incorporating governance into forest transition frameworks to understand and influence Cambodia's forest landscapes. Forest Policy and Economics 96:19-27. https://doi.org/https://doi.org/10.1016/j. forpol.2018.08.003

Riggs, R. A., J. D. Langston, J. Sayer, S. Sloan, and W. F. Laurance. $2020 b$. Learning from local perceptions for strategic road development in Cambodia's protected forests. Tropical Conservation Science 13:1940082920903183. https://doi.org/ https://doi.org/10.1177/1940082920903183

Ros-Tonen, M. A., J. Reed, and T. Sunderland. 2018. From synergy to complexity: the trend toward integrated value chain and landscape governance. Environmental Management 62:1-14. https://doi.org/10.1007/s00267-018-1055-0

Sari, D. A., J. Sayer, C. Margules, and A. K. Boedhihartono. 2019. Determining the effectiveness of forest landscape governance: a case study from the Sendang landscape, South Sumatra. Forest Policy and Economics 102:17-28. https://doi.org/10.1016/j. forpol.2019.01.014

Sayer, J., C. Margules, A. K. Boedhihartono, T. Sunderland, J. D. Langston, J. Reed, R. Riggs, L. E. Buck, B. M. Campbell, K. Kusters, C. Elliott, P. A. Minang, A. Dale, H. Purnomo, J. R. Stevenson, P. Gunarso, and A. Purnomo. 2016. Measuring the effectiveness of landscape approaches to conservation and development. Sustainability Science12: 465-476. https://doi. org/10.1007/s11625-016-0415-Z

Sayer, J., T. Sunderland, J. Ghazoul, J.-L. Pfund, D. Sheil, E. Meijaard, M. Venter, A. K. Boedhihartono, M. Day, C. Garcia, C. Van Oosten, and L. E. Buck. 2013. Ten principles for a landscape approach to reconciling agriculture, conservation, and other competing land uses. Proceedings of the National Academy of Sciences 110:8349-8356. https://doi.org/10.1073/pnas.1210595110

Scheidel, A. 2016. Tactics of land capture through claims of poverty reduction in Cambodia. Geoforum 75:110-114. https:// doi.org/10.1016/j.geoforum.2016.06.022

Scott, J., and P. J. Carrington. 2011. The SAGE handbook of social network analysis. SAGE publications, Thousand Oaks, California, USA. https://doi.org/10.4135/9781446294413

Shackleton, S., F. Paumgarten, H. Kassa, M. Husselman, and M. Zida. 2011. Opportunities for enhancing poor women's socioeconomic empowerment in the value chains of three African non-timber forest products (NTFPs). International Forestry Review 13:136-151. https://doi.org/10.1505/146554811797406642

Souter, N., J, V. Simpson, A. Mould, J. C. Eames, T. N. Gray, R. Sinclair, T. Farrell, J. A. Jurgens, and A. Billingsley. 2016. Will the recent changes in protected area management and the creation of five new protected areas improve biodiversity conservation in Cambodia? Cambodian Journal of Natural History 1:1-5.

Travers, H., K. Winney, T. Clements, T. Evans, and E. MilnerGulland. 2015. A tale of two villages: an investigation of conservation-driven land tenure reform in a Cambodian Protection Forest. Land Use Policy 43:186-196. https://doi. org/10.1016/j.landusepol.2014.11.007
Wenger, E. 1999. Communities of practice: learning, meaning, and identity. Cambridge University Press, Cambridge, UK. https:// doi.org/10.1017/CBO9780511803932

West, P., J. Igoe, and D. Brockington. 2006. Parks and peoples: the social impact of protected areas. Annual Review of Anthropology 35:251-277. https://doi.org/10.1146/annurev. anthro.35.081705.123308

World Bank. 2019. Cambodia. World Bank Group. [online] URL: https://www.worldbank.org/en/country/cambodia 


\section{Appendix 1}

Table A1.1 Description of key network concepts and statistical metrics used in the analysis

\begin{tabular}{ll}
\hline \hline Metric & Description and utility in Actor Network Analysis \\
\hline Modularity & Identifies clusters in the network, a grouping of nodes that are \\
& more strongly connected than in a random network. Clusters in \\
& networks may indicate homophily and poorly connected segments \\
& of networks. \\
Betweenness Centrality & Describes the centrality of a node based on its position between \\
& two disconnected nodes. An actor with high betweenness centrality \\
& may provide a link across disconnected segments of a network and \\
& be effective for diffusing information across a larger network. \\
& Measures a node's influence based on its connection to other \\
influential nodes. High eigenvector centrality indicates an actor's & proximity to influential actors based on their centrality in the \\
& network. \\
Indicates how accessible every other node is from a single node in \\
the network. A node with high closeness centrality is able to \\
transfuse information at a faster pace than other nodes in the \\
network. \\
Measures the degree to which a node clusters in a network. The \\
average clustering coefficient of a network describes how likely the \\
nodes cluster together (average of individual clustering \\
coefficients). \\
Measures the centrality of a node in a network by how many other \\
nodes it is directly connected to (number of edges). An actor with \\
high degree may have high importance and influence in a network. \\
Identifies central nodes within a network for a specific purpose - to \\
disrupt (fragment) the network by the removal of nodes, or to \\
diffuse information/attitudes throughout the network.
\end{tabular}

